\title{
Should reversibility be assessed in all asthmatic children with normal spirometry?
}

\author{
To the Editor:
}

Spirometry is usually normal at baseline in asthmatic children referred for pulmonary function tests (PFTs) [1]; however, a positive response to bronchodilator can be evidenced in these children [2, 3]. The detection of a significant bronchodilator response (BDR) is not meaningless as it confirms asthma and independently predicts subsequent level of forced expiratory volume in $1 \mathrm{~s}$ (FEV1) [4], response to inhaled corticosteroids [5] or correlates to increased exhaled NO [6].

The probability of a positive BDR [7] decreases with increasing values of baseline spirometry indices [5] and should be rare in asthmatic children free of acute exacerbation who exhibit a normal baseline spirometry [8]. For practical use, we aimed to determine pulmonary function indices thresholds to refute a reversibility test in these children. [7]. We hypothesised that, in these specific children, a positive BDR could reveal either a mild central airway obstruction with $\mathrm{FEV}$ //forced vital capacity (FVC) just above the lower limit of normal (LLN), or a mild presentation of small airway obstructive syndrome defined by an FVC reversibility of $10 \%$ or greater $[7,9,10]$. According to these hypotheses, a positive BDR would be associated with similar total lung capacity (TLC), but increased residual volume (RV) to TLC ratio and resistance compared to a negative BDR [9].

We retrospectively assessed the following in asthmatic children: 1) the prevalence of positive BDR; 2) sensitivity and specificity of baseline spirometry indices to detect a positive BDR; and 3) the complementary information given by independent indices of abnormal pulmonary function.

All asthmatic children's files between 2009 and 2017 were extracted from the PFT database (declared to the French authority for data protection, CNIL) of Trousseau University Hospital (Paris, France). All children were referred with a medical diagnosis of asthma (in $93.5 \%$ of the cases by a paediatric pulmonologist or allergologist of our tertiary hospital) for a first or for a follow-up test. After baseline measurements, children were systematically tested with a bronchodilator ( $400 \mu \mathrm{g}$ of salbutamol via a Vortex spacer (Pari, Starnberg, Germany), except if a bronchial hyperresponsiveness test was prescribed. All PFTs were performed according to the American Thoracic Society/European Respiratory Society recommendations (recording of the best of at least two reproducible flow-volume loops, of the median of five interrupter resistance (Rint) measurements or of the mean of the median of three series of specific airway conductance ( $\mathrm{sGaw}$ ) measurements) $[11,12]$ and took place at least $6 \mathrm{~h}$ after the last dose of short-acting bronchodilator in children free of acute exacerbation. PFT indices were expressed as Z-scores for spirometry (LLN: -1.64), sGaw (LLN: -1.96) and Rint (upper limit of normal (ULN): +1.96) $[8,12,13]$. In Caucasian children, static lung volumes were analysed and expressed as percentage of predicted value [13].

Children with normal baseline spirometry (FVC, FEV1 and FEV1/FVC >LLN) and positive BDR (i.e. $\geqslant 12 \%$ baseline $\mathrm{FEV}_{1}$ increase) [7] were compared with children with normal baseline spirometry but negative BDR using a Z-test (large sample and normal distribution). The correlation between baseline FEV1 and post-bronchodilator FEV1 change was studied (Pearson correlation coefficient). The ability of pulmonary function indices to distinguish positive from negative BDR cases was determined after constructing receiver operating characteristic (ROC) curves.

@ERSpublications

In asthmatic children with normal baseline spirometry, a significant reversibility is detected in only $4.9 \%$ of cases http://ow.ly/RrBK30k9WIs

Cite this article as: Dufetelle E, Bokov P, Delclaux C, et al. Should reversibility be assessed in all asthmatic children with normal spirometry? Eur Respir J 2018; 52: 1800373 [https://doi.org/10.1183/13993003.003732018]. 
Among a total number of 8586 PFT performed for asthma, 7750 (90.3\%) had a documented post-bronchodilator spirometry during the study period (the remaining files corresponded to failures in the post- bronchodilator spirometry or to bronchial challenges). Baseline spirometry values were within the range of normal in 5238 files (67.6\% of files with BDR), of which $49 \%$ corresponded to a unique test per child and the others to mainly two (20\%) or three (13\%) PFTs per child (18\% with more than three PFTs).

Characteristics of patients and results of PFT are provided in table 1.

The frequency of inhaled corticosteroids (ICS) prescription was significantly lower in tests displaying a positive BDR compared with tests displaying a negative BDR $(\mathrm{p}<0.0001)$. In all the study files, baseline FEV1 (Z-score) significantly but moderately correlated to FEV1\% baseline change $(\mathrm{r}=-0.24 ; \mathrm{p}<0.0001)$. The proportion of tests with a positive BDR was 4.9\% (95\% CI 4.3-5.5) among which 17.2\% (95\% CI 12.6-21.8) had a change in FVC $10 \%$ or greater versus 0.5 (95\% CI $0.4-0.8)$ in tests with negative BDR

TABLE 1 Characteristics of the 5238 pulmonary function tests with normal baseline spirometry according to bronchodilator response

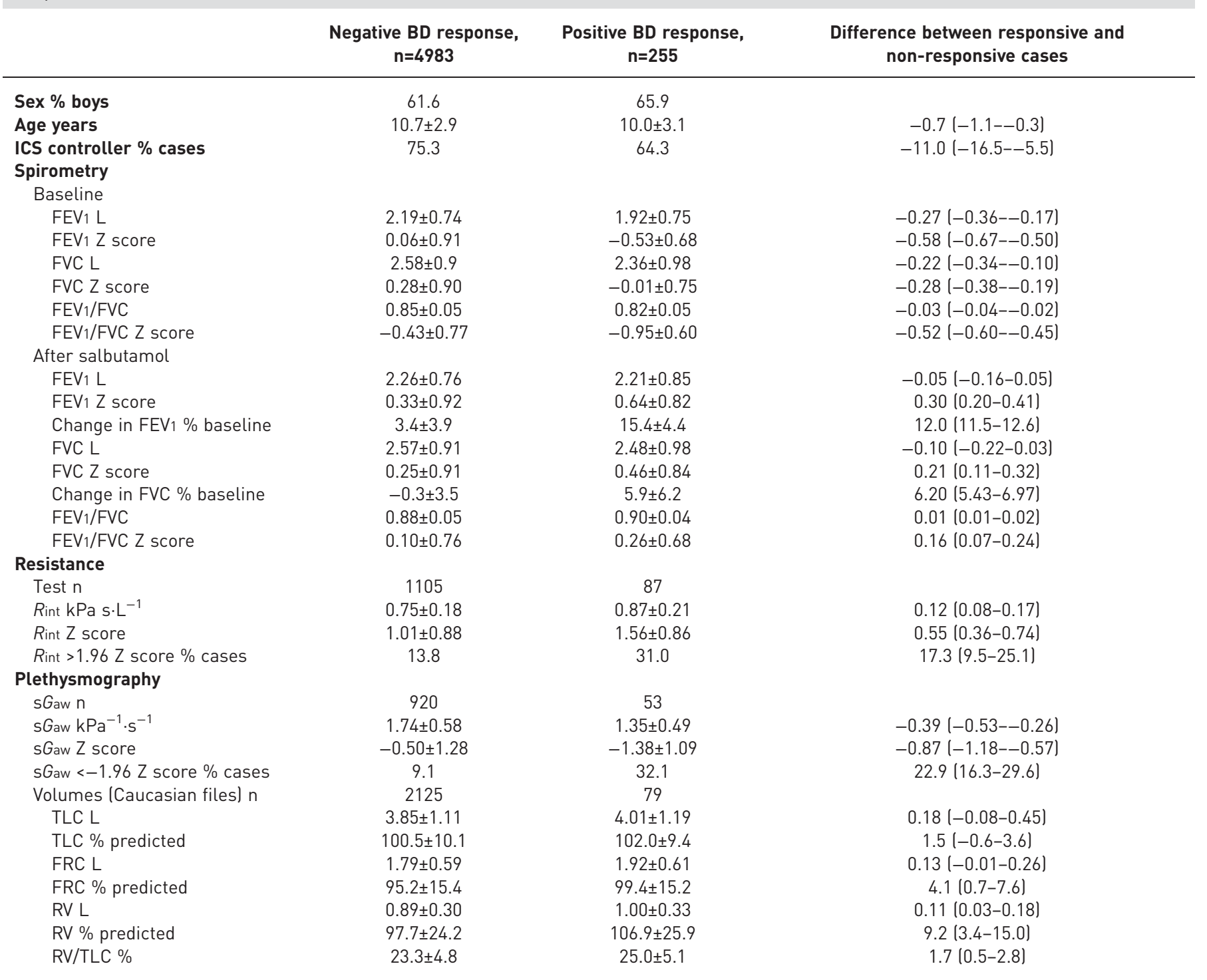

Data are presented as mean \pm SD or difference $(95 \% \mathrm{CI})$, unless otherwise stated. Data are from 5238 pulmonary functions tests in 2343 children: 1149 were tested once; 474 were tested twice; 302 children were tested three times; and 418 were tested more than three times. BD: bronchodilator; ICS: inhaled corticosteroids; FVC: forced vital capacity; FEV1: forced expiratory volume in $1 \mathrm{~s}$; Rint: interrupter resistance; sGaw: specific airway conductance; TLC: total lung capacity; FRC: functional residual capacity; RV: residual volume. 
$(\mathrm{p}<0.0001)$. When baseline Rint or $\mathrm{s} G$ aw were abnormal a positive BDR was observed in $15.1 \%$ (95\% CI 9.9-20.3) and $16.8 \%$ (95\% CI 9.5-24.1) of cases, respectively.

ROC analysis displayed similar areas under the curve (AUC) for baseline FEV1, FEV1/FVC, Rint and sGaw to discriminate between positive and negative BDR tests (AUC 0.69 (95\% CI 0.56-0.83); 0.71 (95\% CI $0.58-0.85)$; 0.68 (95\% CI 0.62-0.74) and 0.71; (95\% CI 0.64-0.78), respectively; all p<0.0001).

Thresholds of 0.42 Z-score for FEV1 or -0.16 for FEV1/FVC enabled to detect $90 \%$ of PFTs with a positive BDR, and would lead to test BDR in $68.1 \%$ (positive likelihood ratio: 1.35 ) and $67.4 \%$ (positive likelihood ratio: 1.36) of the cases, respectively.

The vast majority of children referred for asthma to our PFT department by paediatric sub-specialists had a normal baseline spirometry, and yet they were systematically tested for BDR because predicted normal ranges have limitations. Our routine PFT practice follows international recommendations and the present results should be transposable to other centres following these recommendations but the proportion of children with normal baseline spirometry or a positive BDR might change according to the reliability of the pre-test diagnosis.

The proportion of children with positive BDR and normal spirometry in our study was lower than that evidenced in controller-naïve asthmatic children (19\%) [2] or in children under ICS and in stable condition (10\%) [3]. In our study we could not infer the correct use of ICS from the recorded prescription nor did we had access to asthma symptom control in the previous month, but it is most likely that ICS decreased BDR through the improvement of children's pulmonary function in these children free of acute exacerbation. One child contributed to a unique PFT in half of the files but we did not delete files from children with repeated measurements because a consistent bronchodilator response is a rare phenomenon in children with asthma (5\% during a four-year follow-up [14]) and may not have introduced a major bias in the prevalence of positive BDR.

In our study, the functional pattern of children with positive BDR was consistent with the presence of a borderline central obstruction (lower FEV1/FVC and sGaw, higher Rint) which did not exclude the possibility of a more peripheral obstruction characterised by the absence of reduction of FEV1/FVC because of a concomitant decrease in forced expiratory volumes (lower baseline and more reversible FVC in the positive BDR tests) $[10,15]$. Furthermore, in Caucasian subjects, TLC (\% predicted) values were similar in both groups, while positive BDR cases had significantly higher static volumes in favour of pulmonary distension (table 1) [15].

In conclusion, in our population, not testing bronchodilator in children with normal baseline spirometry would lead to miss a positive BDR in $4.9 \%$ of the cases and measuring baseline resistance or sGaw could help to select children with an increased probability of positive BDR. Our results require further validation in independent populations before using the proposed thresholds $(0.42 \mathrm{Z}$-score for FEV 1 and -0.16 Z-score for FEV1/FVC) to skip BDR assessment in asthmatic children with normal baseline spirometry.

Edouard Dufetelle ${ }^{1}$, Plamen Bokov ${ }^{2,3,4}$, Christophe Delclaux ${ }^{2,3,4}$ and Nicole Beydon ${ }^{1,5}$

${ }^{1}$ APHP, Unité Fonctionnelle de Physiologie-Explorations Fonctionnelles Respiratoires Pédiatrique, Hôpital Armand Trousseau, Paris, France. ${ }^{2}$ AP-HP, Hôpital Universitaire Robert Debré, Service de Physiologie Pédiatrique, Paris, France. ${ }^{3}$ INSERM, UMR1141, Hôpital Universitaire Robert Debré, Paris, France. ${ }^{4}$ Université Paris Diderot, Sorbonne Paris Cité, Faculté de Médecine, Paris, France. ${ }^{5}$ INSERM U938, Centre de Recherche Saint Antoine, Paris, France.

Correspondence: Nicole Beydon, Unité Fonctionnelle de Physiologie-Explorations Fonctionnelles Respiratoires (EFR), Hôpital Armand-Trousseau 26 Avenue du Docteur Arnold Netter, 75571 Paris Cedex 12, France.

E-mail: nicole.beydon@trs.aphp.fr

Received: Feb 212018 | Accepted after revision: May 202018

Conflict of interest: None declared.

\section{References}

1 Bacharier LB, Strunk RC, Mauger D, et al. Classifying asthma severity in children: mismatch between symptoms, medication use, and lung function. Am J Respir Crit Care Med 2004; 170: 426-432.

2 Galant SP, Morphew T, Newcomb RL, et al. The relationship of the bronchodilator response phenotype to poor asthma control in children with normal spirometry. J Pediatr 2011; 158: 953-959.

3 Baatenburg de Jong A, Brouwer AFJ, Roorda RJ, et al. Normal lung function in children with mild to moderate persistent asthma well controlled by inhaled corticosteroids. J Allergy Clin Immunol 2006; 118: 280-282.

4 McGeachie MJ, Yates KP, Zhou X, et al. Patterns of growth and decline in lung function in persistent childhood asthma. N Engl J Med. 2016; 374: 1842-1852.

5 Tantisira KG, Fuhlbrigge AL, Tonascia J, et al. Bronchodilation and bronchoconstriction: predictors of future lung function in childhood asthma. J Allergy Clin Immunol. 2006; 117: 1264-1271. 
6 Mahut B, Trinquart L, Bokov P, et al. The link between exhaled NO and bronchomotor tone depends on the dose of inhaled steroid in asthma. Respir Med 2010; 104: 945-950.

$7 \quad$ Pellegrino R, Viegi G, Brusasco V, et al. Interpretative strategies for lung function tests. Eur Respir J 2005; 26: 948-968.

8 Quanjer PH, Stanojevic S, Cole TJ. Multi-ethnic reference values for spirometry for the 3-95-yr age range: the global lung function 2012 equations. Eur Respir J 2012; 40: 1324-1343.

9 Chevalier-Bidaud B, Gillet-Juvin K, Callens E, et al. Non specific pattern of lung function in a respiratory physiology unit: causes and prevalence: results of an observational cross-sectional and longitudinal study. BMC Pulm Med 2014; 14: 148.

10 Sorkness RL, Zoratti EM, Kattan M, et al. Obstruction phenotype as a predictor of asthma severity and instability in children. J Allergy Clin Immunol 2017; in press [https://doi.org/10.1016/j.jaci.2017.09.047].

11 Miller MR, Hankinson J, Brusasco V, et al. Standardisation of spirometry. Eur Respir J 2005; 26: 319-338.

12 Merkus PJ, Stocks J, Beydon N, et al. Reference ranges for interrupter resistance technique: the Asthma UK Initiative. Eur Respir J 2010; 36: 157-163.

13 Zapletal M, Samanek T, Paul T. Lung Function in Children and Adolescents - Methods, Reference Values. Basel, S. Karger AG, 1987.

14 Sharma S, Litonjua AA, Tantisira KG, et al. Clinical predictors and outcomes of consistent bronchodilator response in the Childhood Asthma Management Program. J Allergy Clin Immunol 2008; 122: 921-928.

15 Sorkness RL, Bleecker ER, Busse WW, et al. Lung function in adults with stable but severe asthma: air trapping and incomplete reversal of obstruction with bronchodilation. J Appl Physiol 2008; 104: 394-403. 